\title{
American Yoga: The Shaping of Modern Body Culture in the United States
}

\section{Sarah Schrank}

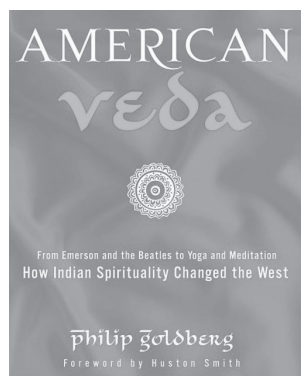

AMERICAN VEDA:

From Emerson and the Beatles to Yoga and Meditation-How Indian Spirituality Changed the West. By Philip Goldberg. New York: Harmony Books. 2010.
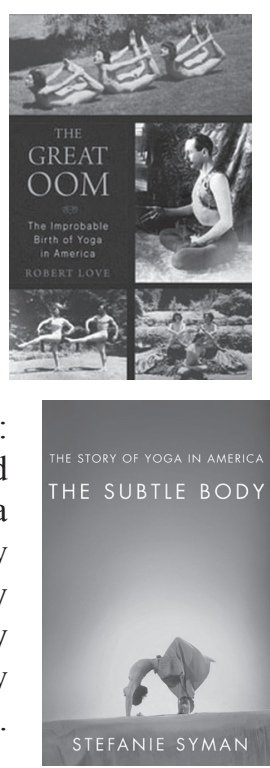
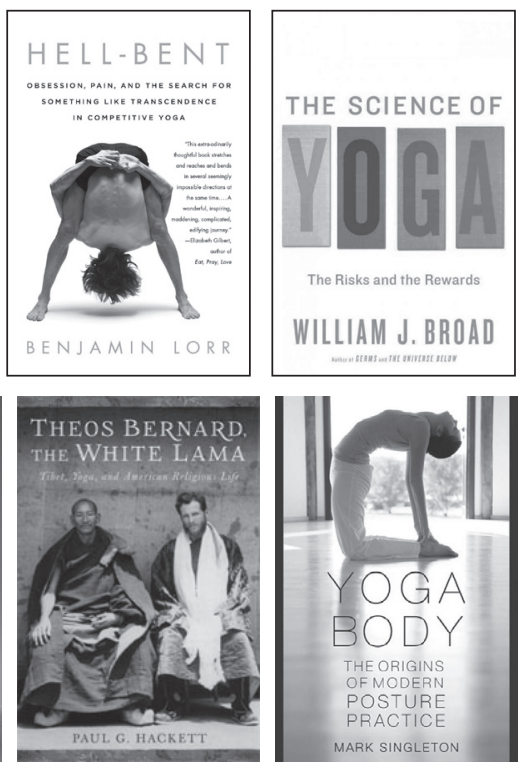

THE GREAT OOM: The Improbable Birth of Yoga in America. By Robert Love. New York: Viking. 2010.

HELL-BENT: Obsession, Pain, and the Search for Something Like Transcendence in Competitive Yoga. By Benjamin Lorr. New York: St. Martin’s Press. 2012. 
THE SCIENCE OF YOGA: The Risks and the Rewards. By William J. Broad. New York: Simon and Schuster. 2012.

THE SUBTLE BODY: The Story of Yoga in America. By Stefanie Syman. New York: Farrar, Straus and Giroux. 2010.

THEOS BERNARD, THE WHITE LAMA: Tibet, Yoga, and American Religious Life. By Paul G. Hackett. New York: Columbia University Press. 2012.

YOGA BODY: The Origins of Modern Posture Practice. By Mark Singleton. New York: Oxford University Press. 2010.

In a recent issue of The Baffler, cultural critic Jorian Polis Schutz points out the unfortunate truth that "yoga," translated from Sanskrit to mean the "union" of body and spirit, has taken hold on a mass scale in America just as labor unions are newly beleaguered politically and economically. While the public idea of uniting the laboring body and spirit to a social warrant of corporate responsibility has weakened, the private investment in an individual union of body and psychic harmony has increased exponentially. ${ }^{1}$ Yoga Journal's widely cited 2012 market study reports that over twenty million Americans practice yoga regularly and spend $\$ 10$ billion a year on related classes, clothing, travel, and equipment. ${ }^{2}$

The popularity and profitability of yoga's inward focus reflects other related trends such as a national obsession with obesity that, public advisories about caloric content aside, ultimately defines health as a private concern tied to individual responsibility and personal consumer choices. ${ }^{3}$ Even as we move toward a kinder and more inclusive healthcare system in the United States, its application still emphasizes individual behavior and cost-cutting, such as pushing employees in employer-paid plans to lower their blood pressure and lose weight; the most progressive insurance plans in fact prescribe yoga for heart health. Add to this a market for yoga-related jewelry, scents, and furniture and one could make the case that the capitalization on American illness has utterly reshaped an ancient system of Indian spiritual meditation, ripping it from its complex historical roots and replanting it in the shallow earth of corporate profit-sharing. Yet, amid the new studio franchises and Lululemon outlets, there are also organized efforts to move yoga out of the marketplace through donation-only studios, free classes, and community service. These are growing rapidly in Southern California, where I live and practice yoga, and Schutz pins his hopes for a new social movement on this emergent union between yoga's physical practice and a sense of collective responsibility. ${ }^{4}$ Given the malleability of yoga as an American cultural form, we should not be surprised that it can be molded to a neoliberal ethos of individualism and an equally powerful urge to collectively transcend crass materialism.

This enormous yoga growth industry has spawned an equally large interest in the history of yoga, its healing potential, and our cultural connection to India, nowhere better showcased than in the Smithsonian's upcoming exhibition Yoga: The Art of Transformation. ${ }^{5}$ This interest is not new; the study of the foundational Hindu spiritual text, the Bhagavad Gita, for example, was a source of intrigue for nineteenth-century American intellectuals, most famously Ralph Waldo Emerson, 
who wrote in 1831 that "it was the first of books; it was as if an empire spake to us, nothing small or unworthy, but large, serene, consistent, the voice of an old intelligence which in another age and climate had pondered and thus disposed of the same questions which exercise us." " In American Veda: From Emerson and the Beatles to Yoga and Meditation-How Indian Spirituality Changed the West, Philip Goldberg draws a direct line from Emerson's transcendentalism and vast intellectual curiosity to contemporary yoga practice in the United States. For Goldberg, yoga is part of a Hindu spiritual tradition consisting of myths, texts, meditation, dietary practices, and philosophy that has traveled for almost two hundred years from India to the United States permeating many aspects of American culture including literature, fashion, and music.

From Emerson's study of the Gita, Goldberg traces the spread of Hinduism and its accompanying Vedic texts though varieties of late nineteenth-century New Thought, including Ernest Holmes' "Science of Mind" and Madame Blavatsky's Theosophical Society, arguing for an Indian connection to American modernist forms of mind-body spirituality, before discussing the influence of Swami Vivekananda. Vivekananda's appearance at the 1893 Columbian Exposition's Parliament of Religions in Chicago has been long accepted by historians to be the cultural watershed by which Hinduism and raja yoga (meditative practice rather than physical) were introduced to American audiences. Vivekananda, an energetic lecturer and traveler, who exchanged eastern spirituality for western capital to fight colonial rule and institute social reform in India, grounded yoga permanently in America when he established the Vedanta Society in San Francisco in 1899. For Goldberg, Vivekananda's savvy application of Hindu ideas to American religious practice would establish "a template for transplanting the core message of Vedantic philosophy into American soil." It is also implied that Vivekananda forged the guru template for United States audiences hungry for spiritual uplift and foreign exotics. From here, in brief, Goldberg traces Vedic legacies through the modernist intellectual traditions of Aldous Huxley and Joseph Campbell; Paramahansa Yogananda's Self-Realization Fellowship; the Beatles, Transcendental Meditation, and the Maharishi; hippies and LSD; the "science" of self-help to our present-day smorgasbord of yoga studios, meditation retreats, kirtan festivals, trendy diets, and exercise regimens that include asanas (postures) and pranayama (breathing exercises). American Veda is a fun read, remarkable in its encyclopedic sweep and a useful introduction to yoga's spread through the west, but its analysis comes up short when one considers the historical context in which Vedic ideas were received in the United States. Goldberg collapses together scholarly nineteenth-century theological exploration with twentiethcentury New Age culture across time and the dissemination of Vedic principles outward, across space, so that everyone from J.D. Salinger to Rhonda Byrne (of The Secret fame) are part of one, cosmically-united enterprise. This approach neither acknowledges the fact that Hinduism is only one of the many religious practices that have attracted American spiritual aficionados (the late twentiethcentury embrace of Jewish Kabbalah is another example), nor does it consider 
that the American interest in Veda was part of a far broader global exchange of modernist, cosmopolitan ideas.

Goldberg's perception of the transplantation of an authentic Indian cultural form to an immature, but welcoming, American context is not unique to American Veda; it is commonly accepted in circles of yoga practitioners that what we do in studios and at retreats here in the United States is somehow inferior, more self-involved, and certainly more commercial than any yoga found in India. While not suggesting American yoga practice isn't narcissistic, in Yoga Body: The Origins of Modern Posture Practice, Mark Singleton offers a radically different perspective on its relationship to India. He argues that the modern physical practice that we consider hatha yoga in the Americas and Europe "is not the outcome of a direct and unbroken lineage...." ${ }^{8}$ Rather, contemporary yoga emerged from an Indian desire to modernize an old and, to Brahmin and Europeans alike, distasteful legacy of conjurers, magicians, and contortionists. Performing yogis caught the eye of nineteenth-century European observers who wrote tracts and treatises reflecting awe at the physical prowess on display and discernable horror at its freakishness, such as when ascetics lay on beds of nails, grew a lifetime's worth of dreadlocks, or folded themselves into impossible postures. As David Gordon White has documented in his foundational work, Sinister Yogis (2009), yoga's roots are not grounded in the Bhagavad Gita and the Yoga Sutras; yoga is much older and tied to ancient tales of yogis' supernatural powers. ${ }^{9}$ To resist British rule and reshape a new Indian national identity, Hindus chose to clean up and repackage yoga "as the flower of Indian culture and Hindu religion." 10 Singleton suggests that "posture-based yoga as we know it today is the result of a dialogical exchange between para-religious, modern body culture techniques developed in the west and the various discourses of 'modern' Hindu yoga that emerged from the time of Vivekananda onward." " For English-speaking Indian gurus intent on presenting a modern Hinduism to the world, the traditional posture practice with its associations with hucksterism and magic was inappropriate for transnational cultural exchange. Instead, yoga was presented as meditative, modern, and even scientific, with little in common with the physicality and contortionism of the ascetics.

The mystery, then, for Singleton, is how did the gurus' painstakingly refreshed version of yoga come to absorb a vanquished physical practice and, by extension, how did this modern form become palatable for American audiences hungry for Indian spirituality? The answer is that, like the United States and Europe, India also encountered western physical culture, which tied eugenics, national identity, class anxieties, and the body to the new industrialism of the nineteenth century. As physical strength became less important for survival in industrial society, the body became more important as a site for identity formation and purveyor of information to increasingly anonymous urban dwellers. Singleton notes, in a fascinating section on the international physical culture movement, that the regimens of famed bodybuilder Eugene Sandow and body faddist Bernarr Macfadden, publisher of Physical Culture magazine, "enjoyed an 
unparalleled vogue in India from the turn of the century onward. In combination with home-grown health and fitness regimes, [bodybuilding] was instrumental in shaping the 'indigenous' exercise revival from which modern postural yoga would issue." 12 As modern Indian yoga appropriated western calisthenics, strengthening the Indian body in both cultural and physical resistance to British rule, a new specimen of yogi emerged. Rather than the transgressive fakir, yogis emerged as models of Indian citizenship with sculpted physiques, muscular prowess, and eager followers. It was from this mélange of cultural practices-Indian meditation and breathing practices, Hindu spirituality, and western purposive exercise- Singleton asserts, that modern yoga sprung. By the mid-1920s and 1930s, hatha yoga had become adequately established to be streamed into the physical systems created by innovators like T. Krishnamacharya (Mysore Ashtanga, associated now with Sri K. Pattabhi Jois), Bishnu Ghosh (sequential hatha series, most commonly practiced in Bikram Choudhury's "hot yoga" classes), and others who would shape posture patterns into their own "schools of yoga." Singleton's Yoga Body makes many contributions to the history of yoga in the west but his most important intervention is to utterly disrupt any claims to an "authentic" yoga in India, much less America; unlike American Veda's emphasis on a seamless, transplanted Indian spirituality, Yoga Body presents a set of physical and meditative practices subject to the same forces of modernity as any other American or European cultural form.

Part of the repudiation of superstition and sorcery was couching yoga in modern science, a feat begun in the 1840s by Bengali surgeon, Dr. N. C. Paul, who studied yogis' seemingly otherworldly ability to suspend their breathing for extended periods of time, noting the therapeutic potential of slowing the intake of oxygen and, more importantly, the exhalation of carbon dioxide. ${ }^{13}$ How yoga has since been both assimilated into medical science and subject to unflattering scientific scrutiny is the focus of William J. Broad's fast-paced The Science of Yoga: The Risks and the Rewards. Lambasted mercilessly by the American yoga community after an excerpt provocatively entitled "How Yoga Can Wreck Your Body" ran in the New York Times, Broad has actually done what American yogis have requested for years: taken the practice seriously as a form of mental, physical, and spiritual therapy. ${ }^{14}$

One of the many delights of Broad's study is his reminder that yoga's origins are also in Tantra, the belief that sex is the simplest path to ecstatic spiritual enlightenment. No small part of yoga's disrepute, Tantra survived as an ancient, and popular, sex cult well into the twentieth century. While American yogis are taught in introductory classes that the original purpose of physical yoga, the asanas, was to permit Hindu monks to sit comfortably still in meditation, the breathing, rocking, and physical stimulation of kundalini yoga suggest other physiological effects at work. In the chapter "Divine Sex," Broad culls the scientific literature on sex and yoga, including studies linking female orgasm and yogic breathing; yoga's autoerotic effects; and the relationship between postures and sexual health. One especially thorough medical study reported that "novice 
yogis told of improvements in all categories of sexual experience under investigation - including desire, arousal, orgasm, and satisfaction." ${ }^{15}$ This is heady stuff, especially when one considers that what research teams were studying were common postures combined with the breathing exercises standard in many yoga classes. The reason for the increase in practitioners' sexual health was the relationship between the parasympathetic and sympathetic responses of the nervous system, with a balance struck between a relaxed, restive state and an adrenaline-infused "frenzy of tension, breathing, and pounding activity, as well as soaring heart rates and blood pressure." 16

As exciting as the erotics of yoga might be, the main effects of yoga on the body are more mundane, but potentially more important. One of the great claims of yoga teachers everywhere is that yoga's rhythmic breathing floods the lungs and bloodstream with oxygen, rejuvenating mind and body. Moreover, and key to much of yoga's attraction as a regular form of exercise, is the belief that yoga increases metabolism and cardiovascular activity, encouraging heart health and weight loss. Broad points to a variety of articles, studies, and exercise programs that claim incorporating yoga into one's regimen will burn calories and reshape the body. When one seemingly authoritative study affirmed these claims in the 1990s, an entire new market in fitness yoga was born: "One of the flashiest promoters was YogaFit, a commercial style that originated in Los Angeles. . . Beth Shaw, its founder, claimed that the vigorous style focused minds, trimmed fat, toned bodies, and provided 'a tough cardiovascular workout.' Her promotional literature, when enumerating the fitness benefits of the style, cited the number one payoff as "cardiovascular endurance." ${ }^{17}$ As persistent an idea as this continues to be, Broad argues instead that a closer look at more accurate science reveals the opposite to be true. Not only does yoga not radically improve cardiovascular performance, it actually lowers metabolism, a fact N. C. Paul uncovered in his primitive experiments on the effects of yogic breathing on the body.

Broad is quick to note that while yoga might not be the secret to skinniness or Ironman-level athletic performance, there is plenty of credible evidence that it positively affects blood pressure, bone health, stress levels, sleep patterns, anxiety disorders, and depression. And, as any longtime yoga practitioner can attest, a regular practice can create such body awareness as to encourage weight loss through a better diet, increase strength and flexibility through repetition of movement, and reduce stress through practiced stillness and meditation. These features have, for many, led to much healthier lives and better fitness, but not because of yoga's cardiovascular effects. This is a tough realization for Americans who want calorie burn in exchange for dedicated physical exertion and a single exercise to accomplish all of one's fitness goals.

In addition to having the above beneficial effects on body and mind, when incorporated into physical therapy regimens, yoga also can help heal acute and chronic injuries. Learning to balance the stretching and relaxing of specific muscles, usually under the watchful eye of an experienced practitioner, promotes 
the repair of common shoulder, back, and neck complaints. In the chapter "Healing," Broad draws a sharp distinction between trained medical professionals, aka MD's with verifiable credentials, and yoga therapists, who may or may not have any medical training at all. In a section of The Science of Yoga at least as controversial as that on yoga's injury risk, Broad takes to task an industry he feels has been negligent in standardizing and regulating a field purporting to be, in fact, a type of therapeutic medical practice. Even if a yoga therapist is a highly skilled healer, it is hard for us to know "because the United States has no regulatory body for yoga therapy. None. Zip. Nada. Few countries do. The field is, on the whole, completely unlicensed and unregulated. Even so, the yoga community has managed to foster the illusion that the United States has a system in place for the accreditation of yoga therapists. That New Age fiction is helping to promote the field's growth. Unfortunately, it is also deceiving people, some desperate for healing because of serious illnesses and injuries. ${ }^{\prime 18}$ Broad's frustration is palpable because he believes that yoga does heal and his research points to the science that proves it. And, furthermore, a program of yoga therapy that carefully monitors one's range of motion and incremental progress can be life changing for people whose physical limitations prohibit participation in yoga classes. Unfortunately, with no regulatory control, it's difficult to know who is legitimate and who is not. And with grandiose claims rampant in the commercial health and fitness fields, yoga runs the danger of appearing a potentially hazardous con.

American yoga's relationship to showmanship, if not outright fraud, is long and colorful and at the heart of the story are the Bernards, Pierre and Theos, the biographical subjects of Robert Love's The Great Oom: The Improbable Birth of Yoga in America and Paul G. Hackett's Theos Bernard, The White Lama: Tibet, Yoga, and American Religious Life. Pierre Bernard, the Iowa-born Perry Baker, reinvented himself in the early twentieth-century as a yogi with tremendous powers of self-hypnosis, which he sold to "anyone who wished to enroll at the College of Suggestive Therapeutics and learn the secrets of what he called 'trained occultism." ${ }^{19}$ Love's history of Bernard's rise to fame and notoriety as the founder of the Tantrik Order in San Francisco in 1900, his stint in jail for sexual impropriety, and his establishment of the physical culture camp and artists' retreat, the Clarkstown Country Club (CCC) in Nyack, New York, reads like a soap opera of socialites, circus freaks, and health faddists. While focused primarily on Bernard's wheeling and dealing with families like the Vanderbilts, The Great Oom captures an element of east coast 1920s bohemianism that is rare in cultural accounts of the era. It is weird and wonderful to read of folk singer Pete Seeger's early childhood spent in Nyack with his parents and two brothers: "The Seegers ... fit nicely into the demographic of the growing Clarkstown Country Club membership: talented young people a bit perplexed by the times and bright enough to be interested in the larger matters of life. The terrible futility of the Great War had given rise to serious philosophical yearnings for Connie and Charles [Seeger], as it had for many of their contemporaries. In Bernard they found not just a teacher but a veritable savior. ${ }^{, 20}$ At the peak of his powers, Bernard hosted 
professional baseball teams and elephants at his camp, lectured on free love to packed audiences, and advised Hollywood stars on the yogic path to a better life. Stymied by the Great Depression, Pierre Bernard would be shoved off his throne as the king of American yoga when his half-nephew, Theos, attracted national attention for five months of spiritual study in Tibet. As Love puts it, "the myth of the White Lama was born, perfectly timed to supplant Bernard's legendary fame as the once dangerous Oom the Omnipotent." ${ }^{.1}$

Theos Bernard has proven one of the more elusive characters in the history of American yoga, celebrated in the 1930s for his physical beauty, intellectual gravitas, travels to Tibet and India, publications (especially Hatha Yoga: The Report of a Personal Experience), and his disappearance and presumed murder in the Punjab in 1947 at age 39. Unfortunately, Paul G. Hackett's dense biography does little to lift the shroud of mystery surrounding the self-described White Lama. Multitudinous and lengthy passages from primary sources disrupt the narrative while a lack of broader context makes what could be a fascinating tale of transnational exchange and personal gain into a mess of names. While Hackett's research of archival collections is impressively thorough, it is difficult to tell where Theos Bernard's actual adventures ended and where his deceptive self-promotion began because there is not enough analytical framing of the story. It's simply hard to gauge what is happening in Hackett's account. In some way, perhaps, Theos'shadowy place in the canon speaks to a larger irony that, at some peril to their reputation, American yogis have historically sidestepped scientific and cultural legitimacy while Indians worked diligently for over a hundred years to shed yoga of its association with magic and hucksterism in favor of scientific validity.

In her highly readable history, The Subtle Body: The Story of Yoga in America, Stefanie Syman traces other such transmutations of yoga in the United States. The subtle body, Syman explains is the "network of channels (nadis) and wheel-like vortices (chakras)" that is distinct from the physical body and key to transforming "mere human flesh into a vehicle for the divine." The purpose behind hundreds of years of hatha yoga was the control and channeling of the subtle body through the vessel of the physical. ${ }^{22}$ It is remarkable, Syman notes, that this foreign and seemingly esoteric practice has had such popularity in the United States accepting, as we must, that its American form has morphed from anything that we might consider "authentic" Indian yoga. With a yoga-in-America origin story similar to that of Goldberg's American Veda, tracing the transcendentalists through Vivekananda's 1893 appearance at the Chicago World's Fair, The Subtle Body soon moves in another direction. Of particular interest to Syman is how American fans, often rich and female, created environments hospitable to yoga's practice and dissemination, shaping celebrity gurus in the process. Pierre Bernard, the subject of Robert Love's The Great Oom, occupies a chapter while Theos is depicted as a more legitimate scholar of yoga's deepest principles, establishing himself as a highly sought after, and expensive, teacher. Though it would later turn out that Theos had fabricated many of his exotic foreign adventures, he "disdained 
Pierre Bernard's 'bread and circuses,' and he wanted to steer well clear of the ceaseless gawking and outright derision, the multiple legal entanglements, and questionable business dealings that had plagued Pierre and his club."23

Though Syman does not directly connect the Bernard family with myriad other gurus, either Indian or American, who set up shop in the United States before World War II, the implication is that altogether the cult of celebrity yoga grew, attracting Americans of means such as President Woodrow Wilson's daughter, Margaret. In this intriguing section, Syman outlines how a woman of such elite social status, barely a generation past the winning of women's suffrage, could follow her guru to India where she became Nistha Devi, and spend the rest of her life on an ashram before dying in Pondicherry in $1944 .{ }^{24}$

But the question arises, of course, as to how the relatively esoteric spiritual pursuits of the wealthy progressed to produce a physical yoga practice wildly popular with middle-class Americans. Goldberg addresses this directly with his discussion of Self-Realization Fellowship founder, Paramahansa Yogananda, his 1946 publication of the best-selling Autobiography of a Yogi, and his brilliant mass-marketing of mail-order yoga guides: "The Self-Realization Fellowship Lessons were the spiritual equivalent of the groundbreaking Sears Roebuck catalog, the Amazon.com of the era." ${ }^{25}$ Syman does little with Yogananda beyond pointing out his significant contribution to establishing Los Angeles as the center of American yoga and his wide appeal to intellectuals and writers like Christopher Isherwood and Gerald Heard. For Syman, the mainstreaming of American yoga began in earnest when the Latvian Eugenie Peterson studied with the great yogi Krishnamacharya in Mysore, reinvented herself as Indra Devi, and set up shop on Hollywood's Sunset Boulevard in 1947. ${ }^{26}$ Coming from a professional dance background, Devi taught a yoga practice that resembles what we do in hatha classes today. According to Syman, Devi "taught a form of yoga that was intensely physical and made purifying your body the necessary first stage of spiritual training. As a result, Devi's yoga-Hatha Yoga - met far more of the needs of Hollywood seekers, especially female ones, who were under constant pressure to look radiantly youthful, than did the yoga you'd encounter at the Vedanta Society."${ }^{27}$ Devi's physical approach, her belief that exercise prolonged youth (as demonstrated in her best-selling 1953 publication Forever Young, Forever Healthy: Simplified Yoga for Modern Living), and her celebrity clientele turned yoga into an appropriate exercise regimen for everyone from Marilyn Monroe to suburbanites keen to shed unwanted weight. Syman notes that when the hippies and their psychedelic leaders Allen Ginsberg and Timothy Leary went looking for spiritual enlightenment in the 1960s, they "didn't need to plumb ancient or obscure texts. All they needed to do was pull out a book geared toward middleclass housewives and peer inside." 28

It is significant that the "psychedelic sages," cheating though they might have been by using LSD and other psychotropic drugs, restored yoga to the kind of meditative transcendence that American and Indian yogis had been working for years to convert to a systemic physical practice. One of Syman's closing points 
is that this difficulty in balancing the physical, spiritual, and psychological would doom yoga in the 1970s and 1980s, diminishing its popularity to the point of parody; yoga would have little place in the world of the Jane Fonda workout, yuppie materialism, cocaine, and other cultural manifestations of Reagan's sped-up corporate America. Not only were the hippie associations of "yoga, with its promise of physical-psycho-spiritual transmutation [a] far too hopeful endeavor for this generation [. . .], presenting yoga as physical fitness had far more deleterious effects. What had at first seemed a tactically savvy moveyoga was no longer threatening and foreign - had made the discipline quite vulnerable. Now people were just as apt to compare yoga to jogging or aerobics as they had been in an earlier generation to compare it to Zen." ${ }^{29}$ Making yoga more physical simply put it in competition with new exercise fads; making yoga more meditative and spiritual suggested flaky New Age-ism. Syman suggests in the book's conclusion that yoga's resurgence in the 1990s was not the result of baby boomers returning to the fold in search of gentler exercise; instead, its newfound popularity was the result of yogis BKS Iyengar, Sri K. Pattabhi Jois, and especially Bikram Choudhoury successfully marrying the individualism and religiosity of American society to ritualistic, and punishing, physicality with the promise of personal improvement, longevity, and bodily health. Somewhere out of the mess of voodoo economics, aerobics, NAFTA, globalization, and the end of the Cold War, yoga returned, newly invigorated with the legitimacy of exercise science, materialism, and flattering workout pants.

The extremes to which Americans can take twenty-first-century yoga are documented in Benjamin Lorr's riveting tale of his own transformative experience, Hell-Bent: Obsession, Pain, and the Search for Something Like Transcendence in Competitive Yoga. With Yoga Journal's soothing pastel palette and "everyone-can-do-it" presentation quickly established as the cushy end of the yoga spectrum, Lorr opens his book with a harrowing account of Backbending Club, in which yogis train for competition by walking their hands up and down a wall, squeezing themselves into tighter and tighter backward folds. The workouts are competitive, performed in secret, and painful: "At least three of the women bending on the wall next to me have little blue X's of surgical tape peeking out from below their sports bras. The surgical tape was put there by a chiropractor earlier in the day. The women are doing backbends so severe their ribs are popping out of place. The chiropractor pops them back in and the women return for more backbends. ${ }^{.30}$ Backbending Club is for a select few competitive yogis only; Lorr focuses more attention on the transformative power of a regular Bikram practice, a type of hatha yoga established in the United States in the 1970s by Bikram Choudhury, student of Indian yoga great, Bishnu Ghosh. After three months of regularly practicing and sweating in yoga classes that can be heated to as much as $112^{\circ}$, Lorr lost forty-five pounds, slept less but better, could place his palms on the floor after being unable to touch his toes, and grew lots of new muscle. But rather than Hell-Bent unfolding like so many prescriptive guides to health and enlightenment (which, I have to admit, I was expecting given that the 
front-cover blurb is by Elizabeth Gilbert, author of Eat, Pray, Love), it provides a far more interesting exploration of both the limits and joys of yoga as well as a pretty frank exposé of Bikram Choudhury himself. Notorious for his conspicuous consumption, suing of yoga studios for stealing his posture series, sexually harassing students and employees, and his grueling and expensive (upwards of $\$ 10,000$ per six-week course) teacher-training, Choudhury taps into the traditionally American cult of yoga personality. Lorr writes of his initial encounter with Bikram Choudhury at a teacher-training session of 380 students in San Diego, crammed into an impossibly hot tent:

The throne is befitting only Bikram: lord over this room of plastic and mirrors, prom king of the apocalypse, our very own babbling Lear. The base is a thick black leather sofa chair that looks stolen from a suburban basement. The upholstery long cracked from the humidity and temperature changes, it is accordingly, always draped in several bright orange beach towels. A small table on the right holds a small bowl of hard candy, which Bikram likes to suck on during class to soothe his throat, and a tall glass of water, which will grow almost erotic at our most desperate moments. But the real magic of the throne is above: two ribbed plastic ventilation tubes hang down. They connect to a personal air conditioner, pumping cold air down on Bikram's head as he teaches. ${ }^{31}$

Choudhury's personality traits aside, his yoga franchise continues to attract thousands of new students and, frankly, works wonders for as long as you are willing to put up with the dank carpeted studios, the heat, and the identical twenty-six postures. But even as dedicated a practitioner as Lorr is forced to ask, "How much of the yoga is the yoga?"32 In other words, could another exercise or diet regimen have such dramatic effects? Lorr concludes, provocatively, that much of what we like about yoga is a placebo effect, "because what is clear is if you engage in a protracted Bikram Yoga binge, you will experience some very clear, very demonstrable side effects. They will convince you that something profound and active is going on within you. This would also explain why people in the West, especially the most ardent supporters, become so obsessed with the authenticity and ritual of yoga. The five thousand years of silent open-eyed meditation, chanting, hand gestures, urine drinking, and rigid Sanskrit pronunciations enhance the placebo effect. They enhance our confidence." ${ }^{33}$ And Lorr concludes with the well-taken point that the ancient yogis understood the placebo effect better than anyone - that's what the mind-body connection, or union, behind yoga was all about from the beginning.

American yoga is deeply interwoven into our "alternative" cultural practices and our fitness preoccupations in ways that in any other context might seem contradictory, if not altogether hypocritical. But, if we move beyond the debate 
over American yoga's "authenticity," a debate the titles under review here demonstrate is pointless, we end up in a much more interesting place. In the United States today, yoga is a thoroughly mainstream activity, something seemingly impossible only twenty years ago, and speaks to a sincere desire to feel better and seek a mind-body connection within the materialism of corporate capitalist society. For many Americans, as demonstrated by the twenty million who practice yoga, this is a conflict they can live with. For those who want yoga to mean more, there are social activist groups like Off the Mat, Into the World, which meld global environmental and economic justice movements to local community efforts. ${ }^{34}$ Meanwhile, if you want to practice yoga on a paddleboard with your dog, there's a class for that; if you want to practice in a roomful of nude yogis, you can do that too. Like it or not, yoga is also becoming part of educational curricula; in a July 1, 2013 ruling, a San Diego Superior Court judge ruled that yoga is not a religion and thus appropriate for students in Encinitas, California, ending a Right-led lawsuit to prevent yoga from being taught in public schools. ${ }^{35}$

This recent literature on American yoga lays bare an impressive and genuine effort to grapple with a complicated dynamic between transnational history, cultural appropriation, and therapeutic science that can quickly overwhelm any scholar. Anyone interested in what yoga is or means or can offer will benefit greatly from any of these texts. Missing from all of them, however, is a feminist, class, or race-based analysis of who is participating, and why. Everyone who has taken a yoga class recently will note the disproportionate number of women and, depending on where you are in the country, the cross-section of ethnic groups in the room. None of the works above consider the significance of locality to yoga, significant in a country the size of the United States, nor do they press the point of how yoga can serve as an acceptable, "healthy" form of body scrutiny and discipline for women and men in a society with increasingly narrow body norms and hyper-sexualized body awareness. I believe yoga can save your health, perhaps even your life, and there are other works that suggest precisely how, but it is naïve in twenty-first century America to think that an embodied practice like yoga is functioning outside the commodified and deeply problematic social system of body monitoring and display we encounter every day. ${ }^{36}$

\section{Notes} $38-39$

1. Jorian Polis Schutz, "The State of Stretching: Yoga in America," The Baffler (22: 2013),

2. "Yoga in America," 2012 Market Study, Yoga Journal, http://www.yogajournal.com/press/ yoga_in_america. Accessed May 13, 2013.

3. See Kathleen LeBesco, "Neoliberalism, Public Health, and the Moral Perils of Fatness," Critical Public Health 21:2 (June 2011), 153-164 and Lauren Rauscher, Kerrie Kauer, and Bianca Wilson, "The Healthy Body Paradox: Organizational and Interactional Influences on Preadolescent Girls’ Body Image in Los Angeles," Gender and Society 27:2 (April 2013), 208-230.

4. Schutz, 41.

5. While this review essay addresses only the most recent works on yoga in the United States, the historical and cultural study of yoga includes other fine titles including Joseph S. Alter, Yoga in Modern India: The Body Between Science and Philosophy (Princeton, NJ: Princeton University Press, 2004); Elizabeth De Michelis, A History of Modern Yoga (London and New York: Continuum, 
2004); and Sarah Strauss, Positioning Yoga: Balancing Acts Across Cultures (Oxford: Berg, 2005).

6. Ralph Waldo Emerson, 1831 journal entry, cited in Philip Goldberg, American Veda: From Emerson and the Beatles to Yoga and Meditation-How Indian Spirituality Changed the West (New York: Harmony Books, 2010), 32.

7. Goldberg, 82 .

8. Mark Singleton, Yoga Body: The Origins of Modern Posture Practice (New York: Oxford University Press, 2010), 33.

9. David Gordon White, Sinister Yogis (Chicago: University of Chicago Press, 2009), 39.

10. Singleton, 80.

11. Ibid., 5 .

12. Ibid., 89.

13. William J. Broad, The Science of Yoga: The Risks and the Rewards (New York: Simon and Schuster, 2012), 18-22.

14. William J. Broad, "How Yoga Can Wreck Your Body," New York Times Magazine, January 5, 2012.

15. Broad, The Science of Yoga, 183.

16. Ibid., 184.

17. Ibid., 64-65.

18. Ibid., 150 .

19. Robert Love, The Great Oom: The Improbable Birth of Yoga in America (New York: Viking, 2010), 21.

20. Ibid., 185 .

21. Ibid., 282.

22. Stefanie Syman, The Subtle Body: The Story of Yoga in America (New York: Farrar, Straus and Giroux, 2010), 4-5.

23. Ibid., 139.

24. Ibid., 158.

25. Goldberg, 117.

26. Syman, 180 .

27. Ibid., 183.

28. Ibid.,197.

29. Ibid., 264-67.

30. Benjamin Lorr, Hell-Bent: Obsession, Pain, and the Search for Something Like Transcendence in Competitive Yoga (New York: St. Martin's Press, 2012), 11.

31. Ibid., 146.

32. Ibid., 274.

33. Ibid., 279.

34. http://www.offthematintotheworld.org/. Accessed July 1, 2013.

35. http://www.utsandiego.com/news/2013/jul/01/encinitas-schools-yoga-trial-judge-ruling. Accessed July 1, 2013.

36. Amy Weintraub's Yoga For Depression: A Compassionate Guide to Relieve Suffering Through Yoga (New York: Broadway Books, 2004), for example, is an especially useful and gentle approach to yoga-as-treatment. 
